Wil men echter den tijd aanduiden, in betrekking waarvan het besproken wordt (dit paard, in den zin van het la tst genoemde bijv. etc.) dan heeft het Karo'sch daarvoor andere woorden, die men, zoo men wil, ook aanw. voornw. noemen kan, doch het naar hunnen aard en hunne beteekenis niet zijn. 't Zijn nl. bijwoorden van tijd. Men gebruikt dan' voor deze, 'ndai (of ouder en deftiger 'ndade) ${ }^{1}$, zoo pas, daareven; kalak 'ndai, de zoo pas vermelde persoon; en ook dan gebruikt men nog wel ter versterking enda er bij : kal ak enda 'n d ai, terwijl men voor die bezigt : a - h - 'ndai, daar straks vermeld.

Waar evenwel niet zoozeer nadruk gelegd wordt op het daar-even of voor-eenigen-tijd-vermeld zijn; men dus alleen wil zeggen; "de [vermelde]" daar gebruikt men zeer veel e, zoodat dit woordje inderdaad al mooi op weg is, het bepalend lidwoord te worden. (Wel merkwaardig dat ook in 't Karo'sch juist het $2^{\text {de }}$ der pronom. demonstr. daarvoor gebezigd wordt. Men denke aan ons bep. lidw. en vergelijke met onze aanw. voornw. die, dat, het Hoogd. lidwoord der, die, das. Ook het lidwoord der Rom. talen (Fr. le, Sp. el, Ital. il etc.) zijn oorspronkelijk het Lat. illĕ etc. waarvan trouwens ook de pron. pers. $3^{\text {en }}$ persoon dier talen gevormd ziju.)

Veel vindt men ook in 't Kar. gebruik gemaakt van 'ndoebe, dat beteekent; "vroeger". Het plaatst het bepaalde woord verder in den tijd terug dan "ndai" en wordt niet zelden gebezigd in den zin van "wijlen".

Ook nai en si nai bezigt men gelijk 'nd oebe en als regel heeft men dan aan nog grooter tijdsafstand te denken ${ }^{2}$ ). 't Komt, hetzij enkelvoudig, 't zij herhaald veel voor met $\mathrm{n}$ in i en beteekent dan "voorouders". Ten slotte heeft men nog noerija voor "heel lang geleden", "uit de oude doos".

Opmerking verdient, dat het Tob. in één opzicht rijker is dan 't Kar. Voor het aanw. Kar. e heeft het an, voor e in zijne beteekenis van "de [vermelde]" i, terwijl het ook nog. een e heeft, in den zin van "deze", overigens met beperkt gebruik.

Het gebruik nu der aanwijzende voornw. van plaats in 't Kar. en in het Nederl. loopt niet zoo erg uiteen. Ook in 't Kar. worden

1 Dit is ook wel eene afleiding van het demonstr. woordje 'nda (da). Verg. o. a. kai en kade, apai 
Downloaded from Brill.com๑4/26/2023 $\odot 2: 53: 22 \mathrm{PM}$ via free access 
Downloaded from Brill, com๑4/26/2023 02:53:22PM 
11 "Tah radja nga-h-'ndai, la lap la 'rtoetoer!" "Wie weet was dat (hij van daar straks) geen vorst en we hebben niet naar z'n mĕrga gevraagd!"

$12 \mathrm{Maka}$ mamang mě atekoe radja Kĕsoendoeten 'ndoebe". Mijn hart verkeert in twijfel omtrent dien vorst van Westerland.

13 Idje kap bibi bĕritana, toerang oe bapa 'ndoebe. Dáár (nl. te Koeta Radja) was, volgens zeggen, zijn tante, de zuster van wijlen zijn vader.

14. "Tangar, begoe bapa, endam akoe ngĕlajari toerang sada-ni-ijoga". Hoor, o geest mijns vaders, ik sta op 't punt om mijn broeder "van 'tzelfde span" op te sporen.

15 "Endam!" Ik kom al!

"Enda koe-tjibalkĕn bĕlo" nina ĕrtoto, "zie, ik offer sirih," zeide ze, biddende.

$16 \mathrm{E}$ ĕnggo kĕntja bagedi, ĕlah me kap ija mangan, i-toedoehkĕn.bibina mĕ kapkĕn koe sapo pĕdĕman ${ }^{1}$. Wel, toen het alzoo was, toen hij klaar was met eten, verwees zijn tante hem naar een sapo, waar hij kon slapen.

17 To sitik koe toere nandé! pandang sitik kaka a ĕrsoerdam." "Kom, ga even naar de toere moeder, en verbied onzen broeder daar op de soerdam te spelen.

18 "Koega kawilmoe ena, Pĕngkawil Bĕtoel? Wat is dat toch met dezen je hengelhaak, o P. B.?

19 "Idja ngenda roemah radja?" Waar is hier het huis van den koning?

$20 \mathrm{Oh}$, bĕbĕrekoe kai e, gĕlarna ena kìn atekoe 'mboekboek!" "Ach kom, hoe zou dat mijn bĕbĕre (zusters kind, neef) zijn, aan dezen zijn naam (n.l. van Pĕngkawil bĕtoel) heb ik al 't land!"

21 "Enám, enám e!" nina mĕ kap 'nděharana, la nai bo bijas si moelihna pe děnggo tanĕh endah!" "Zie's an, zie dat 's an!" zeide zijne gemalin; "dit land zou wel eens niet voldoende kunnen zijn als tegengeschenk!"

22 "Rimo adah pĕpagi bĕntĕr kena, mboewe boehwahna, ibas dalin koe laoe e." Gaat morgen vruchten afwerpen,

: Uit bagedi, mangan en pĕdĕman blijkt, dat de verhaler hier een "orang djoeloe" is en wel uit het aan Sub-Toba grenzend gebied. Inderdaad is hij ook van daar afkomstig: In 't gewone Karo'sch (de "tjakap tĕngah") zou men hier vinden: $b a g e . m a ̄ n$ en $p$ ĕd ĕm ěn. 
van dien citroenboom daar, die heeft veel vruchten [die daar] aan den weg naar de rivier (het water).

$23 \mathrm{I}$ - bĕntĕr karah-karahĕn 'ndoebe rimo, de [vermelde] dienaren wierpen citroenen af.

24. Idje nina bĕngkala 'ndai: "di mĕkoewah atendoe man kami mīn deba", nina. Toen zeide de [pas vermelde] klapperaap: "als ge goedhartig zijt, geef ons er dan ook van."

25 Nina si païs "oeloeti kĕrina tare idjoek e." Toen zeide het dwerghert: omwindt het nu met de idjoek [die ze kwamen zeggen, dat ze verzameld hadden].

Als samenstellingen van de aanw. voornw. dienen vermeld te worden de demonstratieve bijwoorden van plats: $a$. die van rust, hier, daar, ginds; $b$. die van beweging, hierheen enz. Men vormt deze door voorplaatsing resp. van het voorzetsel van plaats $i$ en de prepositie van beweging $\mathrm{koe}$, doch dan moet tusschen de prepositie en het pronomen de palataal $\mathrm{dj}^{1}$ ingeschoven worden. Men krijgt dus: idjenda, idje, koedjenda, koedje, koedja. Zeer dikwijls (vooral in de spreektaal) wordt $i$ weggelaten (djenda etc.)

Voor de bijwoorden van plaats, die een beweging van (from) eene plaats te kennen geven, gebruikt men de eerste, gevolgd door nari: idjenda nari etc.

Overeenkomstig de ruimere beteekenis van $e$ kan ook idjè op den tijd slaan, evenals ons daar $=$ toen. Zoo ook beteekent idjenari wel: daarna.

Idja doet ook dienst als vragend bijw. van plaats, wa a r? (soms door een vragend voornw. te vertalen, zie zin 2), dus ook: koedja, waarheen? idjanari, waar van daan? Ook kunnen soms idje en idja vertaald worden door waar in de beteekenis van daar, als bijv. in den zin: "waar Ik ben, daar zal ook Mijn dienaar zijn."

Enkele voorbeelden van 't gebruik dier aanw. bijw. van plaats vindt men in de boven gegeven zinnen (de $\mathrm{N}^{\mathrm{rs}} 2,10,13,19,24$ ). Voor een volledig beeld van 't gebruik zijn deze verre van voldoende, doch omdat deze woorden syntactisch tot de bijw. gerekend moeten worden, is een verdere behandeling hier niet op zijn plaats. 
Downloaded from Brill,com๑4/26/2023 $\odot 2: 53: 22 \mathrm{PM}$ via free access 
Downloaded from Brill,com๑4/26/2023 02:53:22PM via free access 
Downloaded from Brill, come4/26/2023 $02: 53: 22 \mathrm{PM}$ 
kĕpe lolo la kîta bĕne, O, jongere broeder, mijn woord heeft blijkbaar geen ingang bij u gevonden, nu zijn we stellig en zeker verloren.

Bana kal akoe, la 'rtoekoer, Hèm zij ik [tot vrouw] zonder koopsom.

Bĕlólah ba-ng-koe simpĕdi gělgĕl. Geef mij telkens één pědi (pakje van 100) sirih-bladeren.

Di la kīn kĕpe akoe dāt gĕlar 'ndai, dāt mĕrga, dagi ĕmas boewat ba-ng-koe sada tangan badjoe, Als $i k$ dan toch geen naam en geen merrga (geslachtsnaam) krijg, verschaf me dan goud (geld), één mouw vol.

4. De met van omschreven $2^{\text {de }}$ nv.

Oewiskoe kap e, dat kleed is van mij.

"Ise ĕmpoena oewis?" — "Akoe ĕmpoena." - "Van wien is dit kleed?" - "Van mij."

Kam si mada roemah enda? Is dit huis van u? Zijt gij de heer des huizes?

$5 \mathrm{~S}$ a gebruikt als pers. vnw. $3^{\text {de }}$ pers.

Silih mabaïsa koe bĕrnĕh, kita kĕrina 'ngkoeroeksa idas. Zwager brenge hem (Laga Māu) naar het dal, dan gaan wij boven hem (den steen) uitgraven.

'm Boekboek atena ëmpaksa (of ngĕnehĕntja), Hij koestert wrok tegen hem.

Koega dĕnga gĕlah ninta taresa? Wat zullen we nu tot hem zeggen?

B. Het Karo'sch is over 't geheel niet zoo "vormelijk" als vele andere der Indonesische talen, welke vormelijkheid zich inzonderheid openbaart in 't gebruik der pers. voornaamwoorden.

Globaal genomen, verschilt daarom het Karo'sch, wat het gebruik dier vnw. betreft, niet zoo heel veel van 't Nederlandsch. Bij 't bespreken der vnw. voor iederen persoon afzonderlijk zal vanzelf op enkele eigenaardigheden gewezen worden. Hier dus slechts een paar alg e me en e opmerkingen.

$1^{\circ}$ Niet zelden wordt, als het geen verwarring kan geven, het vnw. weggelaten. In zeer bizondere mate geldt dit van 't vnw. $3^{\text {en }}$ pers., doch ook op de andere is het van toepassing.

E maka moekoel, Daarna trouwden [ze].

Pĕpagina mān ka. Den volgenden dag aten [ze] weer. Kai sabapna maka poeloeng? Waarvoor zijn [wij] vergaderd? 
Veelvuldig wordt ook si gebruikt, waar wij een bijv. nw. attributief bezigen. E i-tama koebas kajoe si mĕgandjang, hij plaatste [den vogel] op een hoogen boom.

Niet zelden wordt si weggelaten. O, silih, kam, kai ng ĕ $\mathrm{ka}$ deba i-ĕltĕp kam, mate? $\mathrm{O}$, vrind, gat alles, wa a rop gij met het blaasroer schiet dood?

Kai pe koe-ĕltĕp mate silih! Alles, waarop ik schiet gaat dood, vrind!

Inzonderheid geschiedt dit weglaten voor de ww. met nasaal.

Wat verder het gebruik van si betreft, het treedt zeer dikwijls op zonder antecedent, en dan geeft het weer ons bepaling-aankondigend vnw., gevolgd door 't relatief vnw. Ook wij volstaan dan dikwijls met het betr. vnw. alleen, bv. die ooren heeft om te hooren etc.

Lît mĕ toeri-toerìn si la 'rmĕrga. Er is een verhaal van iemand, die geen mĕrga (geslachtsnaam) had. Man bohanbohan goele si lìt serpina. [Dienende] tot bamboekokers om vleesch in te koken voor hen, die geld hebben. (Dat ook is e zoo gebezigd wordt hebben we boven in een voorbeeld gezien).

Si dient verder als na a m wijzer, vooral van personen doch ook van plaatsnamen: si Sampe, iemand die Sampe heet; Si bolangit, Si Rĕngit-rĕngit (dorpen), dĕlĕng si Piso-piso (een berg) etc.

Eindelijk vormt si tal van zelfst. nw. vooral van ww. doch ook van geheele zinnen: si naroeh, geleider, leidsman, si kĕmbar, bruidsmeisje, si ngidah, getuige, si koe pola, palmwijntappers, si koe djoema, veldarbeiders, si koe a pi, spijzen, si ĕrděmoe o erat noe djaba, "grensdorp".

Als bijw. van ontkenning mag zeer zeker na si het gewone la (ma) gebezigd worden: zie boven: si la 'rmĕrga, doch zeer dikwijls treft men so (se) aan, dit is mooier; si so kĕlijamĕn, de ongerepte. 
oom (u) een hoofddoek meegebracht," zeide ze, "ik heb voor u een baadje meegebracht, ik heb voor u een lang kleed meegebracht," zeide ze,

Koe-bahan lĕbe koeltiapindoe. Ik zal eerst een mandoline voor u maken.

I-bahan bĕngkilandoe lĕbe soerindoe. Je oom zal je eerst een $\mathrm{kam}$ maken.

Lit tjolokndoe? Hebt gij lucifers bij u?

Enta, koe-tĕpa lĕbe pisondoe, Kom, laat ik je eerst een mes smeden.

C. over de pers. vnw. ieder afzonderlijk.

$1^{\circ} \mathrm{Akoe}$. Dit heeft in 't gebruik niets bijzonders. Ook tegen de hoogstgeplaatsten sprekende, kan men van zichzelf gerust a koe bezigen; 't klinkt volstrekt niet oneerbiedig.

$2^{\circ} \mathrm{Ko}$ of, waar er bizondere nadruk op gelegd wordt, ĕngko. 't Gebruik hiervan is in 't Karo'sch zeer beperkt, omdat er haast altijd iets oneerbiedigs en vernederends in ligt. Ofschoon het ook vertrouwelijkheid kan uitdrukken, hoort men het toch zelfs van ouders tot hunne kinderen miuder vaak bezigen dan $\mathrm{kam}$, tenzij men verbiedt of boos is. Ook kan men gerust zeggen, dat het alleen tot de mannelijke kunne gericht wordt.

Van de jeugd echter, die, als overal, weinig kieskeurig is in haar taal, en speciaal bij de Karo's zich liefst van "straattaal" bedient, is ko een waar troetelkindje.

't Gebruik in 't algemeen is dus heel wat beperkter dan in het Toba'sch, waar anders ook beleefdheidsregelen het gebruik dikwerf verbieden. 't Feit, dat in vele gevallen de Toba's elkaar tutoyeeren (i - pĕrĕngko), waar de Karo's zulks niet doen, verklaren deze laatsten hiermede, dat de Toba-Bataks, die, volgens hen, met de Maleiers `en Karo's van éénén nini afstammen, als oudste der broeders in hun land van oorsprong gebleven zijn, en zich dus om zoo te zeggen steeds "en famille" bevinden.

Een gebruik als in Toba, waar de christenen in 't gebed ook $\mathrm{Ho}$ bezigen (Hd. D u), sprekende tot God, zou in 't Karo'sch stootend zijn. Hun tabas, die tot de "goden" (Dibata) gericht zijn, hebben alle kam. Tegen spoken en geesten (begoe, hantoe e. d.) daarentegen is men zeer onwellevend. Daar is het ko voor en na. 
Downloaded from Brill.com๑4/26/2023 02:53:22PM 
Downloaded from Brill,com 4 4/26/2023 02:53:22PM 
-koe en - ta een nasaal (resp. - ng - en - n-) ingeschoven ${ }^{\mathbf{1}}$ en - moe wordt dan meestal tot $-\mathrm{m}$ verkort. Voorbeelden van een en ander zal men voldoende in de boviengegeven zinnen vinden. Over 't gebruik der pron. suff. behoeft ook niets anders meer gezegd te worden, met uitzondering evenwel van - $\mathrm{na}$, dat door zijue eigenaardige toepassing alleszins een uitvoeriger bespreking verdient. Vooraf nog een paar vermeldenswaardige bizonderheden omtrent enkele andere der pers. aanhechtsels.

$1^{\circ}-\mathrm{koe}$, dit heeft gediend ter vorming van een samengesteld (of wil men: een afgeleid) woord, en wel, toerangkoe. Letterlijk beteekent dit woord "mijn zuster" (v. e. man), "mijn broeder" (v. e. vrouw) en van zijn zuster (ev. broeder) sprekende, wordt het ook in dien zien gebruikt, maar zijn zuster (broeder) a a nsprekende, bezigt men alleen toerang. Nu komt ook toerangkoe als vocatief voor, doch niet jegens zijn zuster, maar jegens de vrouw van z'n vrouws broeder (zwager), dus jegens de aangetrouwde schoonzuster, die het omgekeerd ook bezigt tot haar aangetrouwden schoonbroeder. En dat nu wel degelijk dat -koe tot het woord is gaan behooren blijkt daaruit, dat van die schoonzuster (ev. schoonbroeder) sprekende, het woord nog eens een pron. suffix aanneemt: toerangkoe-ng-koe, to erangkoena etc. mijn schoonzuster, zijn schoonzuster etc.

$2 \circ$ Een tweede pron. suff. dat ook een afgeleid woord gevormd heeft is - ta, althans zoo meen ik de etymologie van adjinta= schoonvader, als eene vrouw van hem spreekt, te-moeten verklaren. M. i. is dit letterlijk a d ji-n-ta, "Onze Heer" (Vorst). $3^{\circ}$ Van kami bestaat een pron. suffix $-\mathrm{nami}$, doch dit is een Tobaïsme of Timoerisme, en 't komt slechts voor achter de titelwoorden radja (Vorst) t o e wan (Heer) en go eroe (medicijnman), dus radjanami, toewannami, goeroenami, inzonderheid als vocatief.

1) Die inschuiving heeft niet plaats, waar de uitgaande klinker eene $e$ of $o$ is. Zie de oorzaak daarvan opgegeven op pag. 3 en 4 van mijn opstel: „Over schrift en uitspraak van het Karo-Bataksch" (Tijdschr. v/h Bat. Gen.

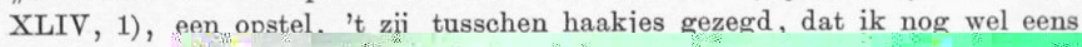


Downloaded from Brill, com๑4/26/2023 02:53:22PM via free access 
Als uitroep gebezigd geeft het dan te kennen, dat die eigenschap in bijzondere mate het deel is van iets of iemand.

Sangapna! Wat is hij gelukkig! Wat boft ie! Hoelina anakndoena! Wat heb je mooie kinderen!

Voorafgegaan door 't praef. -ĕr (rě-) of door 't woordje rěh $=$ komen, geven deze uitdrukkingen een toeneming te kennen: ĕrkĕlĕkna of rĕh kĕlĕkna! 't Wordt hoe langer hoe erger! I-ěltěpna, rěh dĕhĕrna ng' i-bĕntĕrna ěrtěroekna m'. Als hị op hem schoot met het blaasroer, kwam hij al dichter bij, gooide hij [naar] hem, dan kwam hij al lager.

c. In enkele uitroepen, die minachting en ongeloof te kennen geven. De woorden, waarachter - na dan geplaatst wordt, duiden zaken aan van geringe waarde, zooal niet van iets, dat niet bepaald fatsoenlijk is. Bijv. taroek, groente, die meu bij gebrek aan iets beters nuttigt; ${ }^{1}$ djĕring, soort van kastanje (de op Java bekende djengkol), imĕn, snot, patat, aars. De uitdrukkingen: ta roekna, djĕringna etc. beteekenen alle zooveel als ons: je grootje's, je moer's en dergelijke lieflijkheden.

d. Voorts komt - na nog voor in tal van bijw. uitdrukkingen inzonderheid in bijw. bepalingen van tijd en van graad. $\mathrm{Na}$ het bovengezegde is de verklaring niet moeilijk.

Pĕpagina, den volgenden dag; bĕrngina, des nachts (volgende op den dag, waarvan verhaald werd); si-děkahdĕkahna, eeuwig, tot in eeuwigheid, asa bantji-bantjina, zooveel mogelijk, as a kĕsahna, uit alle macht etc.

\section{De reflexieve voornaamwoorden.}

Het Karo'sch berit deze wel, maar maakt er veel minder gebruik van dan 't Hollandsch.

$1^{\circ}$ De zin wordt vaak auders geconstrueerd, en bijv. het reflexivum vervangen door eene omschrijving in den geest als boven bij het pers. voornw. (Zie B. 2).

Nina ibas oekoerna: Hij zeide bij zichzelf.

I-tĕpisua pahana: Zij sloegen zich op de dij.

$2^{\circ}$ De vorm van het werkwoord drukt het wederkeerend begrip uit. Ik denk hier vooral aan de praefixen ĕr-en tji- (over welker eigenlijke beteekenis eerst bij de behandeling der ww. kan

1 Vandaar m ĕtaroek voor waardeloos, tot niets nut, niet in tel. 
Downloaded from Brill.com๑4/26/2023 02:53:22PM 
van batang en diri, die zuiver pleonastisch is. Voorts wordt het refl. voornw. ook nog al eens vervangen door "daging" dat ook "lichaam" beteekent. Men kan dit dus gevoegelijk als eene omschrijving beschouwen, gelijk onder $1^{\circ}$ vermeld.

Als reflexief voornw. is bangkoe, etc. meestal accusatief 1 (lijdend voorwerp) en een voorzetsel is daar dus eigenlijk niet op zijn plaats. Maar evenals in 't Mal, a kan niet zelden gebruikt wordt, waar het overbodig is, vindt men ook in 't Bataksch wel man, waar het feitelijk niet te pas komt. Bijv. (in "Bĕroe Ginting Pase"). "I-pĕmagin-magin ba pana man bana, Haar vader makte zich schijnbaar ziek". (Dit "schijnbaar" ligt in de herhaling van magin), haar vader hield zich ziek; ban a alleen zou beter zijn.

Als eigenaardige spreekwijze mag hier nog vermeld worden "mahan bana", letterlijk "zich maken" voor onze bijwoordelijke uitdrukking "van zelf".

Verder zij het hier de plaats, iets over het wederkeerige (reciproque) voornaamwoord te zeggen, nl. "elkander". Gelet op de samenstelling en het onbepaalde zijner beteekenis, behoort het eigenlijk thuis onder de onbepaalde voornaamwoorden, maar 't is toch aan het reflexieve verwant, zoodat zelfs, gelijk bekend, sommige talen geen onderscheid maken: sich lieben, se rencontrer, etc. Ja, ook in 't Nederlandsch wordt het onderscheid wel eens vergeten, en dat niet alleen in de spreektaal, maar ook door litteratoren: "Ik zag de speren, hier en daar zich naadren aan het Zuid." (Hofdijk).

Het Bataksch nu bezit geen wederkeerig voornw. doch drukt het begrip uit door een bepaalden vorm an het werkwoord te geven (met praef. si - en suff. - ěn). Ter versterking bezigt hẹt dan nog wel pĕkepar of pĕlepar = van beide kanten, van weerszijden, mutuellement, er bij, bijv. sihangkēn pĕkepar, elkander van weerszijden eerbiedigen, doch noodig is dit niet. Ook sapih= "onderling", "gelijkelijk", "beide", dient soms ter uitdrukking van ons "elkander". Ook ligt in veel ww. met het praef. ěr reeds van zelf het wederkeerige begrip opgesloten : ro e b at, met elkaar vechten; ĕrbebe, met elkaar stoeien, worstelen, en zoo tal van ww. die op spelletjes betrekking hebben.

${ }^{1}$ In onderscheiding dus van het pers. vnw., dat in dien vorm datief is. 
Downloaded from Brill.comఠ4/26/2023 $02: 53: 22 \mathrm{PM}$ via free access 
Downloaded from Brill.com๑4/26/2023 $\odot 2: 53: 22 \mathrm{PM}$ 
11 "Tah radja nga-h-'ndai, lalap la 'rtoetoer!" "Wie weet was dat (hij van daar straks) geen vorst en we hebben niet naar z'n mĕrga gevraagd!"

12 Maka mamang mĕ atekoe radja Kĕsoendoeten 'ndoebe". Mijn hart verkeert in twijfel omtrent dien vorst van Westerland.

13 Idje kap bibi bĕritana, toerang oe bapa 'ndoebe. Dáár (nl. te Koeta Radja) was, volgens zeggen, zijn tante, de zuster van wijlen zijn vader.

14. "Tangar, begoe bapa, endam akoe ngĕlajari toerang sada-ni-ijoga". Hoor, o geest mijns vaders, ik sta op 't punt om mijn broeder "van 'tzelfde span" op te sporen.

15 "Endam!" Ik kom al!

"Enda koe-tjibalkĕn bĕlo" nina ĕrtoto, "zie, ik offer sirih," zeide ze, biddende.

16 E ĕnggo kĕntja bagedi, ĕlah me kap ija mangan, i-toedoehkĕn.bibina mĕ kapkĕn koe sapo pĕdĕman ${ }^{1}$. Wel, toen het alzoo was, toen hij klaar was met eten, verwees zijn tante hem naar een sapo, waar hij kon slapen.

17 To sitik koe toere nandé! pandang sitik kaka a ĕrsoerdam." "Kom, ga even naar de toere moeder, en verbied onzen broeder daar op de soerdam te spelen.

18 "Koega kawilmoe ena, Pĕngkawil Bĕtoel? Wat is dat toch met dezen je hengelhaak, o P. B.?

19 "Idja ngenda roemah radja?" Waar is hier het huis van den koning?

$20 \mathrm{Oh}$, bĕbĕrekoe kai e, gĕlarna ena kìn atekoe 'mboekboek!" "Ach kom, hoe zou dat mijn bĕbĕre (zusters kind, neef) zijn, aan dezen zijn naam (n.l. van Pĕngkawil bĕtoel) heb ik al 't land!"

21 "Enám, enám e!" nina mĕ kap 'ndĕharana, la nai bo bijas si moelihna pe děnggo tanĕh endah!" "Zie's an, zie dat 's an!" zeide zijne gemalin; "dit land zou wel eens niet voldoende kunnen zijn als tegengeschenk!"

22 "Rimo adah pĕpagi bĕntĕr kena, mboewe boehwahna, ibas dalin koe laoe e." Gaat morgen vruchten afwerpen,

$\therefore$ Uit bagedi, mangan en pĕdĕman blijkt, dat de verhaler hier een "orang djoeloe" is en wel uit het aan Sub-Toba grenzend gebied. Inderdaad is hij ook van daar afkomstig: In 't gewone Karo'sch (de "tjakap tĕngah") zou men hier vinden: bage. mān en pĕdĕm ĕn. 
Downloaded from Brill.comఠ4/26/2023 02:53:22PM via free access 
vnw. alleen voldoende is om onze constructie van bep. aank. met betr. vnw. weer te geven.

Eindelijk zij nog opgemerkt, dat $\mathrm{kai}$, ise, etc. indien ze als onbep. voornw. optreden meestal voorkomen met de ontkenning (la), dus beantwoorden aan ons niets, niemand, etc. De positieve, iets, iemand, geeft men liever op andere wijze weer. $\mathrm{Kai}$ (kai-kai) en ise, (veelal gevolgd door pe) geven meer weer ons: alles, (wat ook) iedereen, (wie ook) dan iets of iemand.

Enkele voorbeelden tot nadere toelichting.

Ise pe la koe-tandaï djenda; ik ken hier niemand.

Sada bĕrngi kami 'ndjala, tĕngtĕng kai pe la dāt; wij hebben den heelen nacht met het werpnet gevischt, maar niets gevangen.

Ise kal ngasoep moewat manoek-manoek si nanggoer dawa-dawa, bana kal akoe la'rtoekoer. Hij, die (of: alwie) in staat is den vogel N. D. te vangen, zal mij tot vrouw hebben, zonder bruidschat.

Pěrkadena pe ma nai lit. Ook niet 't geringste is er overgebleven; hij is alles kwijt.

De lit dahînndoe, tah kai-kai gija, noehit oekoerndoe koedje; als ge iets te doen hebt, wat het ook zij, wees er met uw gedachten bij. Kai pe i-babana; hij heeft alles meegebracht.

Het aantal onbep. voornw. is in 't Bat. niet groot, d. w. z. die, welke uitsluitend als oubep. onw. optreden. 't Zijn er slechts drie: anoe, kadih en deba. Daarnaast bezigt men andere woorden ook wel als onbep. onw. doch ze zijn dit niet uitsluitend. Dat vele der vragende voornw. aldus kunnen optreden, hebben wij reeds gezien. De behoefte aan onbep. vnw. is niet groot, omdat den Karo's verschillende wegen openstaan om uit te drukken wat wij met de onbep. vnw. doen, gelijk beneden zal blijken, na bespreking van de als onbep. vnw. optredende woorden.

1. A noe. Bezigt men van personen (ook wel van dorpen, rivieren, kortom, die dingen, die een eigen naam hebben), die onbekend zijn, of die men in 't algemeen wil aanduiden; si-Anoe is ons "N. N." "Dinges" en dergel.

2. Kadih. Etymologisch wel een ietwat gewijzigde vorm van het vrag. vnw. kade "wat." Men bezigt dit woord, als men niet terstond op den naam van 't bedoelde voorwerp kan komen, dus 
Downloaded from Brill,comఠ4/26/2023 $\odot 2: 53: 22 \mathrm{PM}$ via free access 
Downloaded from Brill,comఠ4/26/2023 $02: 53: 22 \mathrm{PM}$ 
Downloaded from Brill,comఠ4/26/2023 02:53:22PM 
Veelvuldig wordt ook si gebruikt, waar wij een bijv. nw. attributief bezigen. E i -tama koebas kajoe si mĕgandjang, hij plaatste [den vogel] op een hoogen boom.

Niet zelden wordt $\mathrm{si}$ weggelaten. O, silih, kam, kai ngĕ ka deba i-ĕltĕp kam, mate? O, vrind, gaat alles, wa a rop gij met het blaasroer schiet dood?

Kai pe koe-ĕltĕp mate silih! Alles, waarop ik schiet gaat dood, vrind!

Inzonderheid geschiedt dit weglaten voor de ww. met nasaal.

Wat verder het gebruik van si betreft, het treedt zeer dikwijls op zonder antecedent, en dan geeft het weer ons bepaling-aankondigend vnw., gevolgd door 't relatief vnw. Ook wij volstaan dan dikwijls met het betr. vnw. alleen, bv. die ooren heeft om te hooren etc.

Lìt mĕ toeri-toerín si la 'rmĕrga. Er is een verhaal van iemand, die geen merga (geslachtsnaam) had. Man bohan bohan goele si lìt serpina. [Dienende] tot bamboekokers om vleesch in te koken voor hen, die geld hebben. (Dat ook is e zoo gebezigd wordt hebben we boven in een voorbeeld gezien).

$\mathrm{Si}$ dient verder als na mwijzer, vooral van personen doch ook van plaatsnamen: si Sampe, iemand die Sampe heet; Si bolangit, Si Rĕngit-rĕngit (dorpen), dělĕng si Piso-piso (een berg) etc.

Eindelijk vormt si tal van zelfst. nw. vooral van ww. doch ook van geheele zinnen: si naroeh, geleider, leidsman, si kĕmbar, bruidsmeisje, si ngidah, getuige, si koe pola, palmwijntappers, si koe djoema, veldarbeiders, si koe api, spijzen, si ĕrděmoe oerat noe djaba, "grensdorp".

Als bijw. van ontkenning mag zeer zeker na si het gewone la (ma) gebezigd worden: zie boven: si la 'rmĕrga, doch zeer dikwijls treft men so (se) aan, dit is mooier; si so kĕlijamĕn, de ongerepte. 